\title{
Research on the Financial Management and Risk Control of Small and Medium-sized Enterprises from the Perspective of New Normal of China's Economy
}

\author{
Zerui Xiu \\ Changchun University of Science and Technology, Changchun, 130022, China
}

Keywords: Financial management, Risk control, Small and medium-sized enterprises, New normal

\begin{abstract}
The concept of new normal profoundly reveals the new changes in the stage of China's economic development. The emergence of the new normal of the economy means that China's macro economy has entered a new and more standardized stage of development. Under the background of new normal, small and medium-sized enterprises face the double challenges of financial management and risk control. From the perspective of new normal of China's economy, the paper explores the strategies of financial management and risk control of small and medium-sized enterprises to provide some references for the relevant researchers.
\end{abstract}

\section{Introduction}

Under the new economic norm, with the further development of the enterprise system reform, it is necessary to further strengthen the construction of enterprise financial management. However, under the influence of the new social norm, the internal and external structure of the enterprise has changed at the same time; especially the change of the financial management is most obvious. For the financial management of the enterprise cannot appear any errors, establish stricter financial management system. At the present stage, there will still be some problems in the management of financial work. Enterprises should reduce or avoid problems arising from financial management, strengthen the improvement of enterprise financial management, and improve work efficiency. Under the new normal, the traditional industries are relatively saturated, infrastructure, China Unicom and some new products, new technologies, new formats, new business models, investment opportunities emerge, leading to the trend of investment demand trends. At the same time, the new normal has short slow growth, industrial economic downturn, increased business uncertainty, business risk and financial risk increases, changes to the development of the capital market, to leverage capacity, inventory, cost reduction, supply side reforms and a series of macro environment, the innovation of financial management to enterprise: enterprise the innovation of financial management including financial management concepts, models, methods and evaluation. With the rapid development of China's economy, the competition among domestic enterprises has gradually increased, and the frequency of updating has also been accelerated. Therefore, keen judgment and good management model are the necessary magic tools for an enterprise to remain invincible. In enterprise management, financial management is in a very important position, and it is related to the normal operation and sustainable development of enterprises. In today's economic situation, enterprises must take the correct attitude towards financial management problems, and find scientific and reasonable countermeasures to improve and strengthen. 


\section{Strategies of Financial Management of Small and Medium-sized Enterprises under the Background of New Normal}

Change Concepts of Financial Management. For a long time, China's financial management work must be based on national laws and regulations, fiscal policies and systems to organize related financial activities and deal with the relevant financial relationships. Traditional financial management performs only the work of accounting. With the macro economy of our country has entered a new norm, financial personnel awareness cannot keep up with the development of the market economy situation, the importance of financial management in the enterprise development and the urgency of the lack of comprehensive understanding, cannot make the necessary financial advice for the future development of enterprises and investment direction, which is bound to affect the financial management of enterprises. Under the new normal economy, the concept of financial management should be changed to adapt itself to the changes of the business environment and development strategy under the new normal condition, and the financial management can play its due role in management. To reduce the risk, enterprises should plan scientifically and invest steadily, and choose the investment model according to the financing situation and the scale of capital. Enterprises should combine their own advantages and core capabilities to turn their investment objectives into areas that are familiar or appropriate, increase the percentage of market share, increase the rate of capital recovery, and avoid diversification. The enterprise should not only expand the traditional business channels, but also to face the transformation and upgrading into new areas, new markets and other issues, and then must cash assets, capital operation, direction and operation strategy to make corresponding adjustment. Enterprises in the market competition than service quality. In the face of these changes, financial management should explore new ideas, get rid of the traditional management experience manacle, establish innovative consciousness and awareness, focus on enterprise these changes, pinpoint their location, services in enterprise restructuring and upgrading, to do a good job. Therefore, the change of the concept of financial management is the primary task for the financial management to adapt to the new normal.

Perfect Systems of Financial Management. If the enterprise does not have the standard financial system, it will inevitably lead to inefficient management and wrong decision-making. At present, most of small and medium-sized enterprises in China lack of financial system. In dealing with small and medium-sized enterprises, most countries choose to strengthen their protection and support from the system level, and have achieved great success. Small and medium enterprises promotion law of china. The formulation and implementation of these measures is a powerful measure for the state to promote the development of small and medium-sized enterprises. We should actively develop credit business. Including: to further expand the policy bank for small and medium-sized enterprises and business scope of services; encourage the creation of flexible credit guarantee mode, for example by the government funded the establishment of financial policy guarantee institutions, government and enterprises jointly funded the establishment of membership guarantee institutions or joint-stock guarantee institutions. Efforts to broaden the direct financing channels. Specific practices include appropriate relaxation of restrictions, financing of bond issuance. Encourage all walks of life to establish financing organizations. Establish and improve the social service system for small and medium-sized enterprises, including the training service system. Technological innovation service system. The information service system and credit guarantee and social assessment system will further broaden the financing channels. In view of the micro environment, the following improvements need to be implemented. Speed up the reform of the property right system and realize the survival of the fittest through the flow of property right. We will actively adjust the structure and focus on the types of industries supported by the state. Recruitment of high-quality personnel to improve the technological innovation capability of enterprises. Standardize the internal organization form, establish and perfect enterprise management system. At the same time, we should improve management awareness and make clear the important role of financial management in enterprise operation. 
Enhance Ability of Financial Management. Smooth development of stable sources of capital supply is necessary to maintain the healthy operation of enterprises, and is also the key to ensure long-term stable development of enterprises. For small and medium-sized enterprises, the funds are more important to determine whether they can continue to survive. Because of its historical background and management characteristics, it is difficult for small and medium-sized enterprises to obtain funds from the money market and capital market, and the main external sources of funds must be turned to financial institutions. In recent years, the proportion of bank lending to small and medium-sized enterprises has continued to decline. Enterprise financial management must pay attention to fund management, establish perfect fund management system. Improve the authenticity and accuracy of financial information, and improve the financial information disclosure of enterprises, and form a good financial reputation. Improve the enterprise credit approval and management system, especially the management of enterprise current accounts, improve the efficiency of capital recovery. For example, in the key link card receivables, accounts receivable and inventory strictly overdue, when necessary, can also be linked to the performance of the sales staff, thereby increasing accounts receivable recovery efforts. Strict cost reimbursement system, reduce unnecessary costs, improve corporate capital utilization. The concrete measures are to establish and strictly abide by the examination and approval procedures for expenses approval, and resolutely prohibit false reports, excessive reports and false reports of expenses. Once found, they should be dealt with severely. We should reduce the financing cost and reduce the financial risk by optimizing the debt structure. Management should make a scientific and reasonable financing plan according to the demand of fund, market interest rate and project schedule. We should work out a feasible repayment plan, according to the loan return time, the amount of return to reasonable scheduling of funds, reduce the lack of preparation or failure of capital flow and the delay in repayment losses.

\section{Strategies of Risk Control of Small and Medium-sized Enterprises under the Background of New Normal}

Strengthen Awareness of Risk Control. Risk control, related to the survival and development of enterprises, is also an indispensable part of the enterprise's financial management function. Especially in the new normal economic development, the market competition is becoming more and more fierce, and enterprises from the past quantity expansion and price competition are gradually turning to quality, differentiation based competition. With the increase of market uncertainty, the market mechanism will play a more and more important role, and it will produce risks different from usual. Faced with the increasing risk of this fact, the enterprise financial management only strengthen risk control ability, to withstand all kinds of risks. Maintain a sound financial strategy, rational allocation of asset resources, strengthen the management of liquidity funds, and strengthen the management of profitability. In the context of the new normal economic development, the enterprise's financial management must be fully prepared to improve the financial risk response capability, and promote the healthy development of enterprises. Under the new normal economic policy for the financial management of the enterprise is not all good, once the staff of the new normal economic policy under the master degree is not enough, extremely easy to cause serious financial risk. Therefore, we must pay attention to the risk alert work, avoid illegal work, stimulate the related risks of enterprise finance. The financial personnel who carry out the work must undergo rigorous training and be familiar with the economic policies under the new normal. To ensure that in the financial work, according to the new financial management methods related work to deal with, clear new financial operation process. Increase the degree of attention, to ensure that the audit work from beginning to end, the company's financial operations can be carried out in accordance with the relevant provisions of the new policy, to avoid financial risks.

Establish Systems of Risk Prediction. Small and medium-sized enterprises should establish a whole process of enterprise financial risk prediction system. We collected the basic financial information, a comprehensive understanding of the whole process of business activities, and analyzes the reason of financial risk, to prevent potential crisis management and financial risk, guarantee risk 
can respond effectively, timely adjust business activities. Perfect the early-warning mechanism of enterprise financial risk. Adhere to the tracking and supervision of enterprise operating capital, establish and improve the enterprise financial crisis early warning analysis model. Through the analysis of financial indicators, once the abnormal symptoms of capital operation are found, various contingency measures should be formulated to avoid or reduce risk losses. Strengthen the daily management of enterprise funds. The establishment of strict internal control procedures and control measures, the implementation of major issues reporting system and collective decision-making. The enterprise sets up the approval procedure and authority of the relevant funds in advance. According to the characteristics of the financial activities of SMEs, the early-warning index system can be divided into three categories. One is to reflect the enterprise payment ability index, including the actual payment ability and potential payment ability. The two reflects the enterprise monetary fund structure indicators, including the ratio of its own funds and the balance at the end of the non-monetary funds of its own funds ratio balance and currency funds at the end of the year, and the ratio between the funds and the balance at the end of the monetary fund. Three is to reflect the level of enterprise funds to use, including investment ability to pay and investment financial risk. Financial risk early warning system, refers to the financial management and accounting based on sensitive financial indicators set some scientific and reasonable degree, analysis and evaluation of enterprise financial management level of the use of funds and the real financial situation, timely reveal hidden problems, the potential financial risk status and joint liability risk forecast. The most important thing to construct a financial early-warning system for SMEs is to select some early warning indicators of sensibility so that the early-warning index system can comprehensively and truly reflect the financial risks faced by enterprises.

Reform Tools of Risk Management. Nowadays, more and more attention has been paid to science and technology in every aspect of society. Technology is the first productive force for work. We use high-tech information technology to carry out enterprise financial management and repair some of the confusion in management. For this, must be effective in the enterprise financial management, fully introduce appropriate information technology to efficiently participate in financial management, and then make a substantial contribution to enhance the efficiency and accuracy of risk management. With the rapid development of the Internet era, financial investment also appeared more choice of small and medium-sized enterprises should comply with the requirements of the times, the active use of the Internet resources, improve financial management mode, improve financial efficiency, combined with its own characteristics to choose suitable financing method of accurate measurement, the deviation between the financial management activities of enterprises and control standards, reduce the occupancy of the enterprise funds rate, reduce costs, improve economic efficiency. Small and medium-sized enterprises should analyze the development trend of the financial field under the new normal economy scientifically, and make the financial management play a positive role in leading the new normal in the enterprise management. The financial management system is particularly important for small and medium-sized enterprises, establish a perfect financial management system, financial personnel can strictly follow and as a warning, is also necessary to ensure the smooth conduct of the premise of financial work. The use of funds turnover relates to all aspects of the enterprise, directly affect the enterprise's entire production operations, including the financial sector, enterprises in all departments to use and control of funds paid. We should improve the financial control system, strengthen the operation and management of funds, to enable enterprises to maintain sustained and healthy development, better economic transformation, and adapt to the new normal development requirements.

\section{Conclusion}

Under the new normal, the economy has new development, under the new normal, SMEs are also facing development, transformation, or professional exploration. The finance of small and medium-sized enterprises should keep the position of internal financial management, apply management accounting and cost management idea, pay attention to the risk control in key fields. 
With the new normal, we should keep pace with the times and strive to turn the financial sector from the subsidiary sector into an important management department that can assist the decision-making based on data.

\section{References}

[1] Hu Meilin. Research on Financing Innovation of Small and Medium Enterprises in the Industrial Agglomeration Area under the New Normal [J]. Shanghai Journal of Economics, 2016(5): 58-63+75.

[2] Lu Shun, Wang Zugang. The Research on Issues of Financing of Micro and Small Enterprises under the Background of the New Normal [J]. West China Finance, 2015(5): 16-20+45.

[3] Liu Qi. A Rsearch on the Development Strategies of Science and Technology Finance in the New Normal Background [J]. Journal of Nanchang University (Humanities and Social Sciences), 2017, 48(3): 79-86.

[4] Lei Guangmei, Xu Ping. Research on the Path of Sustainable Development in Small and Micro-sized Enterprises under New Normal Economy [J]. Journal of Changchun University, 2016, 26(3): 19-24. 